\title{
ERRATUM
}

\section{Programmable molecular recognition based on the geometry of DNA nanostructures}

\author{
Sungwook Woo and Paul W. K. Rothemund
}

Nature Chemistry 3, 620-727 (2011); published online 10 July 2011; corrected after print 15 August 2011.

In the version of this Article previously published, in Fig. 2, the series of $1 \mathrm{~s}$ and 0 s on the images were incorrectly placed. Also, in the penultimate paragraph of the section 'Stacking of origami rectangles', the final sentence should have referred to Fig.le,g. These errors have now been corrected in the HTML and PDF versions of the Article.

\section{ERRATUM}

\section{The transcription factor FOXM1 is a cellular target of the natural product thiostrepton}

Nagaratna S. Hegde, Deborah A. Sanders, Raphaël Rodriguez and Shankar Balasubramanian

Nature Chemistry 3, 725-731 (2011); published online 21 August 2011; corrected after print 5 September 2011.

In the version of this Article originally published, the corresponding author should have been listed as Shankar Balasubramanian.

However, the email address was correct. This error has been corrected in the HTML and PDF versions of the Article. 